\title{
The Effect of Cerium Reduction on Light Emission in Cerium-containing $20 \mathrm{Y}_{2} \mathrm{O}_{3}-25 \mathrm{Al}_{2} \mathrm{O}_{3}-55 \mathrm{SiO}_{2}$ Glass
}

\author{
Jee-Hun Maeng and Sung-Churt Choi* \\ Division of Materials Science \& Engineering, Hanyang University, Seoul 133-791, Korea
}

(Received June 11, 2012 : revised September 18, 2012 : accepted September 24, 2012)

\begin{abstract}
The effect of cerium concentration and the addition of $\mathrm{Sb}_{2} \mathrm{O}_{3}$ on the light emission of cerium-contained glass were investigated. The glass matrix composition was $20 \mathrm{Y}_{2} \mathrm{O}_{3}-25 \mathrm{Al}_{2} \mathrm{O}_{3}-55 \mathrm{SiO}_{2}$, the $\mathrm{CeO}_{2}$ concentration ranged from 0.05 to $0.5 \mathrm{~mol} \%$, and $\mathrm{Sb}_{2} \mathrm{O}_{3}$ was added at concentrations of 0.02 to $0.1 \mathrm{~mol} \%$. The $\mathrm{Ce}^{3+}$ and $\mathrm{Ce}^{4+}$ absorption bands were observed at approximately $330 \mathrm{~nm}$ and $240 \mathrm{~nm}$, respectively. A broad emission band at $400 \mathrm{~nm}$, due to the $4 \mathrm{f}-5 \mathrm{~d}$ transition of the $\mathrm{Ce}^{3+}$ ion, was observed under illumination by a UV light at $330 \mathrm{~nm}$. The photoluminescence intensity of $\mathrm{Ce}^{3+}$ had a maximum value at a $\mathrm{CeO}_{2}$ concentration of $0.1 \mathrm{~mol} \%$. Adding $\mathrm{Sb}_{2} \mathrm{O}_{3}$ decreased the $\mathrm{Ce}^{4+}$ absorption intensity and enhanced the light emission intensity of $\mathrm{Ce}^{3+}$ by about $45 \%$.
\end{abstract}

Keywords: Photoluminescence, Glass phosphors, Cerium, Reduction

OCIS codes : (160.4670) Optical materials; (160.4760) Optical properties; (160.2540) Fluorescent and luminescent materials; (160.2750) Glass and other amorphous materials

\section{INTRODUCTION}

High power LEDs have undergone rapid development in recent years. The heat produced by high power LEDs induces deterioration of the transparent resin used for wrapping and fixing the powder phosphors onto the power chip [1]. As an alternative to resin, Tanabe et al. investigated the use of glass-ceramics for a novel durable phosphor for use in LED systems [1-2]. Glass phosphors for use in LEDs have also been investigated by several other research groups [3-5]. In spite of their good thermal durability, applying glass phosphors to LED products is quite difficult, because the light emission intensity and efficiency are relatively lower than those of the crystalline phosphors.

Glass does not have homogeneous site symmetry, therefore, the activator ion experiences a random distribution of local fields and, as a consequence, the light emission intensity is low [6-7]. Several activators also tend to build multivalent ion states in the glass [8-9]. In particular, cerium has two types of ions, viz. $\mathrm{Ce}^{3+}$ and $\mathrm{Ce}^{4+}[9]$. However, only the $\mathrm{Ce}^{3+}$ ion has light emission properties. Therefore, if the $\mathrm{Ce}^{3+}$ proportion is increased in the glass, it is expected that the light emission efficiency of the glass phosphor could be enhanced, and potentially be applied to LED lamps.

The final goal of this study is to enhance the light emission intensity in the cerium-containing glass, by increasing the $\mathrm{Ce}^{3+}$ proportion. This study reports the effects of: 1) cerium concentration; and 2) addition of $\mathrm{Sb}_{2} \mathrm{O}_{3}$ as a reduction agent in cerium-containing $20 \mathrm{Y}_{2} \mathrm{O}_{3}-25 \mathrm{Al}_{2} \mathrm{O}_{3}-55 \mathrm{SiO}_{2}$ glass. To verify such effects, the light emission properties were characterized with various concentrations of $\mathrm{CeO}_{2}$ and $\mathrm{Sb}_{2} \mathrm{O}_{3}$.

\section{EXPERIMENTS}

$20 \mathrm{Y}_{2} \mathrm{O}_{3}-25 \mathrm{Al}_{2} \mathrm{O}_{3}-55 \mathrm{SiO}_{2}$ glass samples were prepared using a conventional quenching method under oxidizing conditions. Commercial $\mathrm{Y}_{2} \mathrm{O}_{3}, \mathrm{Al}(\mathrm{OH})_{3}$ and $\mathrm{SiO}_{2}$ reagent grade powders were mixed by a 3D-turbulent mixer. The mixture was place in an alumina crucible and melted at $1550^{\circ} \mathrm{C}$ for $4 \mathrm{~h}$ in an electric furnace. $\mathrm{CeO}_{2}$ was added to the host glass in the concentration range of 0.05 to $0.5 \mathrm{~mol} \%$ and $\mathrm{Sb}_{2} \mathrm{O}_{3}$ was added from 0.02 to $0.1 \mathrm{~mol} \%$. The prepared glasses were annealed at the glass transition temperature, and thereafter, lapped and polished to $2 \mathrm{~mm}$ thickness and

\footnotetext{
*Corresponding author: choi0505@hanyang.ac.kr

Color versions of one or more of the figures in this paper are available online.
} 
mirror surface. The light absorption spectra were measured by UV-visible (JASCO V-570) and the photoluminescence spectra were measured by PL-spectroscopy (PSI, DARSA Pro-5200, Xe light source) in the reflection mode.

\section{RESULTS AND DISCUSSION}

\subsection{Light Absorption Spectra}

Figure 1 shows the optical absorption spectra of the cerium-containing $20 \mathrm{Y}_{2} \mathrm{O}_{3}-25 \mathrm{Al}_{2} \mathrm{O}_{3}-55 \mathrm{SiO}_{2}$ glasses. Two broad, strong absorption bands were observed in the UV region. $\mathrm{Ce}^{3+}$ exhibited an absorption band at around 330 $\mathrm{nm}$ and a broad absorption spectrum with a maximum value at $240 \mathrm{~nm}$ due to a charge transfer band of $\mathrm{Ce}^{4+}$.

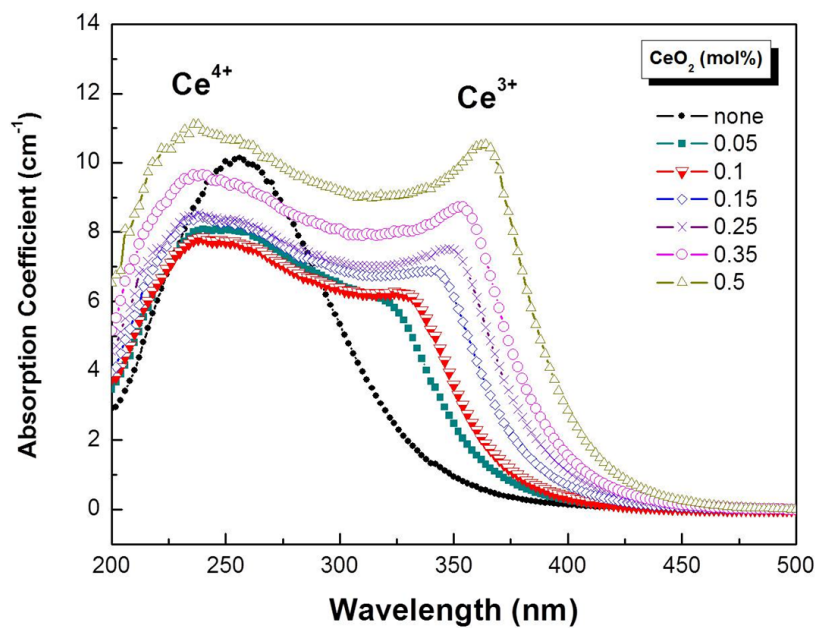

FIG. 1. The optical absorption spectra of cerium-containing $20 \mathrm{Y}_{2} \mathrm{O}_{3}-25 \mathrm{Al}_{2} \mathrm{O}_{3}-55 \mathrm{SiO}_{2}$ glasses. The concentration of cerium oxide ranged from 0.05 to $0.5 \mathrm{~mol} \%$.

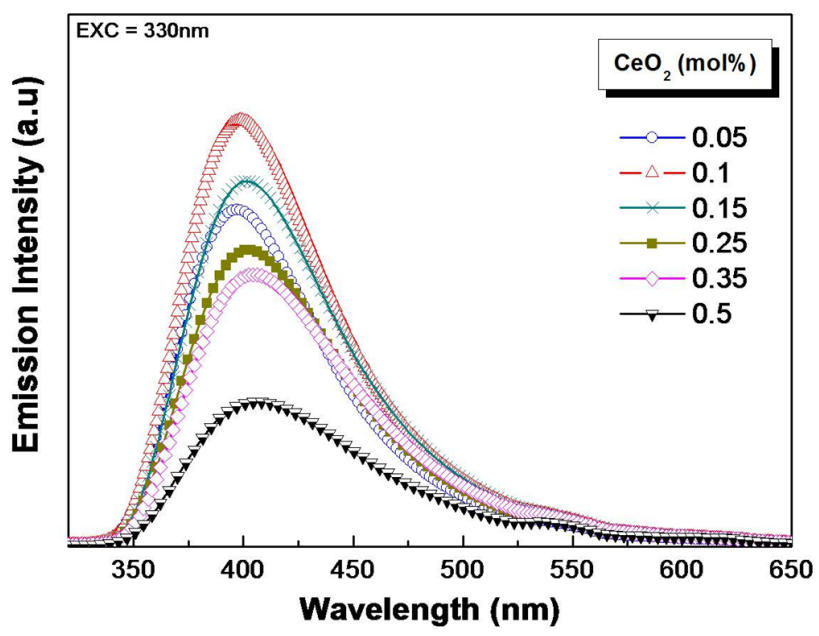

FIG. 2. The $\mathrm{Ce}^{3+}$ photoluminescence spectra of ceriumcontaining $20 \mathrm{Y}_{2} \mathrm{O}_{3}-25 \mathrm{Al}_{2} \mathrm{O}_{3}-55 \mathrm{SiO}_{2}$ glasses. The wavelength of the excitation light is $300 \mathrm{~nm}$. The concentration of cerium oxide ranged from 0.05 to $0.5 \mathrm{~mol} \%$.
The entire absorption intensity was increased and the $\mathrm{Ce}^{3+}$ absorption peak shifted to longer wavelengths as the cerium concentration increased.

Stroud reported a $\mathrm{Ce}^{3+}$ absorption band at $320 \mathrm{~nm}$ and a $\mathrm{Ce}^{4+}$ charge transfer band in the ultraviolet range in sodium-silicate glass [11]. Absorption spectra in this study showed good agreement with previous results (Fig. 1) [7, 10].

Figure 2 shows the $\mathrm{Ce}^{3+}$ emission spectra for different $\mathrm{CeO}_{2}$ amounts. There is a maximum value at approximately $400 \mathrm{~nm}$ upon $330 \mathrm{~nm}$ excitation. The emission intensity increased remarkably at a cerium concentration of $0.1 \mathrm{~mol} \%$. However, the emission intensity gradually decreased at cerium concentrations greater than $0.1 \mathrm{~mol} \%$. The decrease can be attributed to the concentration quenching due to the reduced ion-ion distance and the increased excited state interactions between $\mathrm{Ce}^{3+}$ ions.

Possible modification of the local structure due to increased $\mathrm{CeO}_{2}$ content may be responsible for the red-shift of the absorption and emission band of $\mathrm{Ce}^{3+}$ ions as the additional $\mathrm{CeO}_{2}$ can change the glass structure, producing non-bridging oxygen atoms and altering the covalency and optical basicity of nearby $\mathrm{Ce}^{3+}$ ions [14]. As covalency increases, the interaction between the electrons is reduced, so they spread out over wider orbitals [15]. Consequently, an increase in the covalency will reduce the energy difference between the ground and the excited states. This increase in covalency may lead to a shifting of the emission band and absorption band to a longer wavelength. A similar shift due to optical basicity has been observed in 6s-6p transition of $\mathrm{Pb}^{2+}$ [12]. The study has shown that the increase of optical basicity resulted from an increase of the degree of $\mathrm{Pb}-\mathrm{O}$ covalency and led to the shifting of the absorption band to a longer wavelength. Thus, although the nephelauxetic effect [16] is a plausible cause of the red-shift, further study is required to investigate the changes within the local structure to fully understand the observed behavior.

\subsection{The Effect of Cerium Ion Reduction by $\mathrm{Sb}_{2} \mathrm{O}_{3}$}

Figure 3(a) shows the optical absorption spectra for different amounts of $\mathrm{Sb}_{2} \mathrm{O}_{3}$ in $0.1 \mathrm{~mol} \% \mathrm{CeO}_{2}$ glass. The curves exhibited the typical spectra of $\mathrm{Ce}^{3+}$ ions and $\mathrm{Ce}^{4+}$ ions. The entire absorption intensity was radically decreased by introducing $\mathrm{Sb}_{2} \mathrm{O}_{3}$. A Ce $\mathrm{Ce}^{3+}$ band shift due to changing the amount of $\mathrm{Sb}_{2} \mathrm{O}_{3}$ was not observed.

The addition of $\mathrm{Sb}_{2} \mathrm{O}_{3}$ has a proven reduction effect in the glass, similar to $\mathrm{As}_{2} \mathrm{O}_{3}$ [9]. Kim et al. investigated the effect of $\mathrm{Sb}_{2} \mathrm{O}_{3}$ in cerium-containing lithium-silicate glass and found that, $\mathrm{Sb}_{2} \mathrm{O}_{3}$ is the most effective to reduce the cerium ion, among the various adopted materials in the applied glass system [13]. The cerium is reduced via the following reaction at high temperatures [9]:

$4 \mathrm{CeO}_{2}+\mathrm{Sb}_{2} \mathrm{O}_{3} \leftrightarrow 2 \mathrm{Ce}_{2} \mathrm{O}_{3}+\mathrm{Sb}_{2} \mathrm{O}_{5}$

The $\mathrm{Ce}^{3+}$ absorption spectra of $\mathrm{Sb}_{2} \mathrm{O}_{3}$-containing glasses 

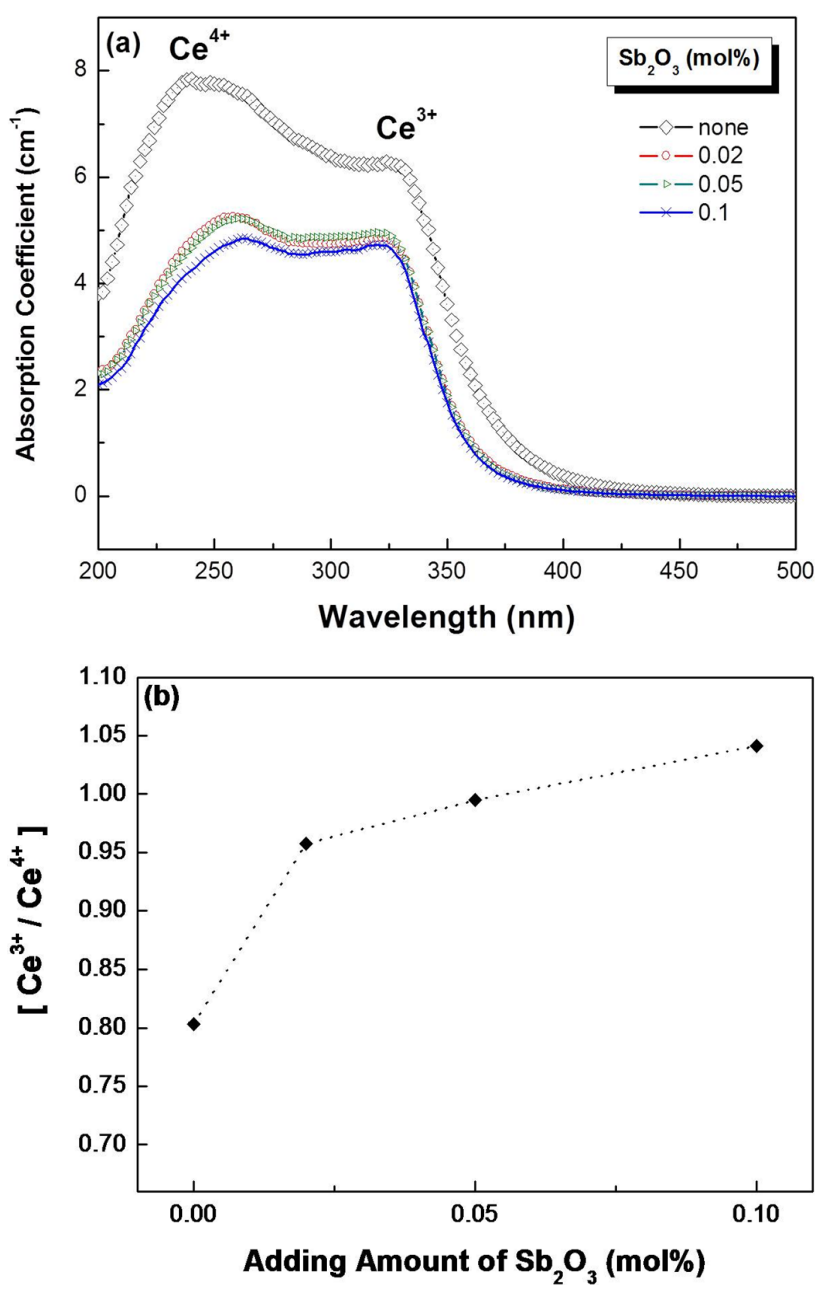

FIG. 3. The optical absorption spectra of $\mathrm{Sb}_{2} \mathrm{O}_{3}$-containing glasses. The cerium oxide concentration is $0.1 \mathrm{~mol} \%$, the $\mathrm{Sb}_{2} \mathrm{O}_{3}$ concentration ranged from 0.02 to $0.1 \mathrm{~mol} \%$. (a) the change of the absorption spectra (b) the fraction of the $\mathrm{Ce}^{3+}$ peak value and the $\mathrm{Ce}^{4+}$ peak value.

showed a similar line shape and distribution and there was no noticeable shift. The overall absorption intensity decreased upon introduction of $\mathrm{Sb}_{2} \mathrm{O}_{3}$. The reduced oscillation strength of the Ce-ions, which was induced by the local environmental change, may be responsible for the change. However, the origin of the overall decrease needs further study. It should be mentioned that the absorption peak due to $\mathrm{Ce}^{4+}$ decreased markedly compared to that of $\mathrm{Ce}^{3+}$. This clearly indicates the role of $\mathrm{Sb}_{2} \mathrm{O}_{3}$ reducing $\mathrm{Ce}^{4+}$ as suggested in equation (1).

Figure 3(b) indicates the value of the $\mathrm{Ce}^{3+} / \mathrm{Ce}^{4+}$ ratio for different $\mathrm{Sb}_{2} \mathrm{O}_{3}$ amounts. This ratio is simply expressed by the fraction of the $\mathrm{Ce}^{3+}$ peak value and the $\mathrm{Ce}^{4+}$ peak value. This calculation method suggested by Kim et al. [13], is useful for estimating the slope of the $\mathrm{Ce}^{3+}$ proportion variation. In this work, the proportion of $\mathrm{Ce}^{3+}$ increased linearly with $\mathrm{Sb}_{2} \mathrm{O}_{3}$ content.

Figures 4(a) and (b) show the excitation and the
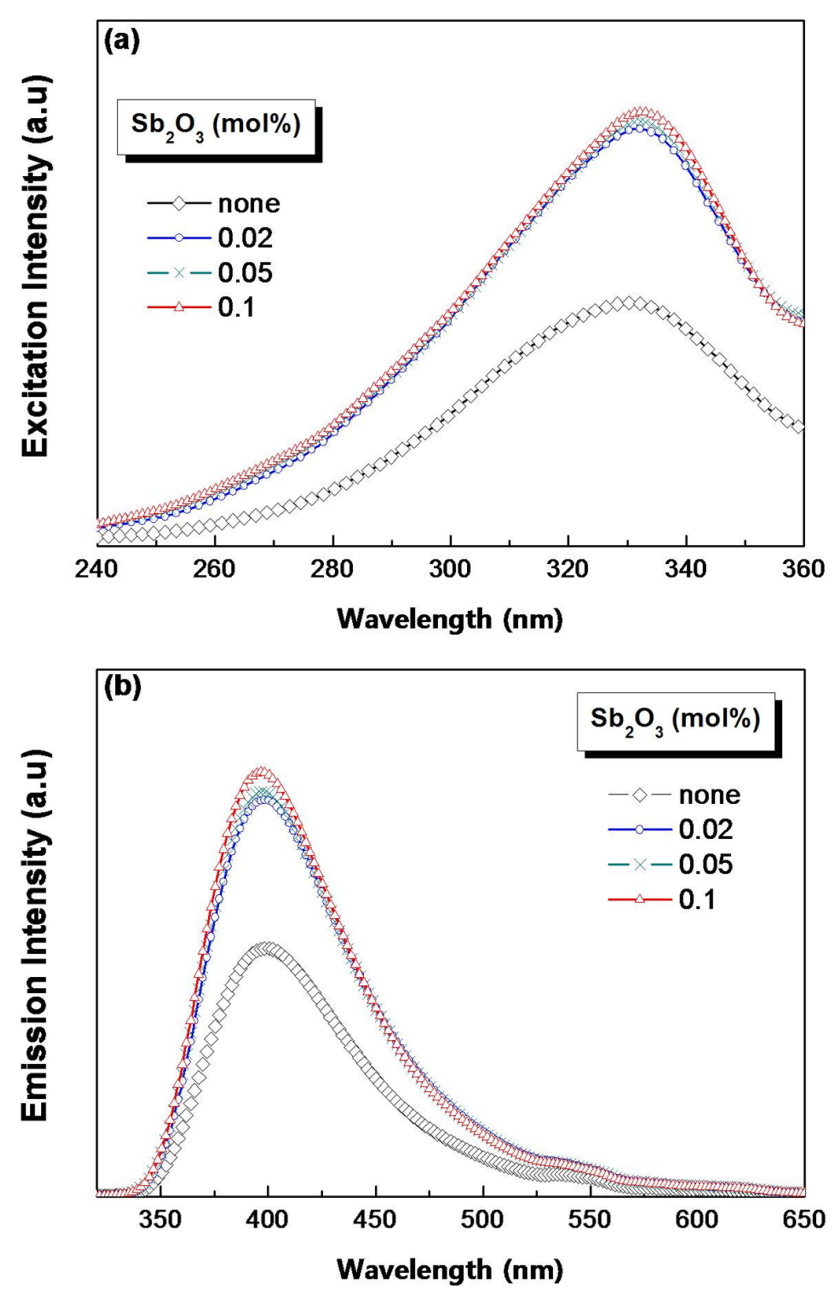

FIG. 4. The photoluminescence spectra of $\mathrm{Sb}_{2} \mathrm{O}_{3}$-containing glasses. The cerium oxide concentration was $0.1 \mathrm{~mol} \%$, $\mathrm{Sb}_{2} \mathrm{O}_{3}$ concentration ranged from 0.02 to $0.1 \mathrm{~mol} \%$. (a) the excitation spectra (b) the emission spectra upon $330 \mathrm{~nm}$ excitation.

emission spectra, respectively, of $\mathrm{Sb}_{2} \mathrm{O}_{3}$-containing glasses. A strong excitation band was observed at $330 \mathrm{~nm}$, regardless of the $\mathrm{Sb}_{2} \mathrm{O}_{3}$ amount. This value corresponded to the $\mathrm{Ce}^{3+}$ band of the absorption spectrum (Fig. 3(a)). The emission spectra exhibited the luminescence of $\mathrm{Ce}^{3+}$ ions with a maximum at $400 \mathrm{~nm}$ upon $330 \mathrm{~nm}$ excitation. Both the excitation and the emission intensity were enhanced by approximately $45 \%$ compared to $\mathrm{Sb}$-free glass. This enhancement is related to the increase of the $\mathrm{Ce}^{3+}$ activator concentration due to the $\mathrm{Sb}_{2} \mathrm{O}_{3}$ effect. As a result, the introduction of $\mathrm{Sb}_{2} \mathrm{O}_{3}$ to cerium-containing glass increased the proportion of $\mathrm{Ce}^{3+}$ ions and enhanced the intensity of the photoluminescence without atmospheric control.

\section{CONCLUSIONS}

Intrinsic light absorption and photoluminescence of cerium- 
contained $20 \mathrm{Y}_{2} \mathrm{O}_{3}-25 \mathrm{Al}_{2} \mathrm{O}_{3}-55 \mathrm{SiO}_{2}$ glass were investigated. The resulting effect of cerium concentration and reduction with $\mathrm{Sb}_{2} \mathrm{O}_{3}$ was then studied.

The $\mathrm{Ce}^{3+}$ absorption band and emission band shifted to longer wavelengths according to an increase of the cerium oxide content due to the nephelauxetic effect. The light absorption intensity of the $\mathrm{Ce}^{4+}$ charge transfer band radically decreased as a result of the cerium ion reduction reaction with the introduction of $\mathrm{Sb}_{2} \mathrm{O}_{3}$. The proportion of $\mathrm{Ce}^{3+}$ was increased gradually and the ratio of $\mathrm{Ce}^{3+} / \mathrm{Ce}^{4+}$ increased linearly by increasing the amount of $\mathrm{Sb}_{2} \mathrm{O}_{3}$. Consequently, photoluminescence intensity was enhanced by approximately $45 \%$ compared to that of Sb-free glass. Therefore, $\mathrm{Sb}_{2} \mathrm{O}_{3}$ is considered an effective reduction additive in the preparation of a glass phosphor that does not require atmospheric control.

This fundamental study is the basis for further investigations with regard to a YAG:Ce glass-ceramic phosphor.

\section{REFERENCES}

1. S. Fujita, S. Yoshihara, A. Sakamoto, S. Yamamoto, and S. Tanabe, "YAG glass-ceramic phosphor for white LED (I): background and development," Proc. SPIE 5941, 594111 (2005).

2. S. Fujita, S. Yoshihara, A. Sakamoto, S. Yamamoto, and S. Tanabe, "YAG glass-ceramic phosphor for white LED (II): luminescence characteristics," Proc. SPIE 5941, 594112 (2005).

3. Z. J. Chao, C. Parent, G. L. Flem, and P. Hagenmuller, "White light emitting glasses," J. Solid. State. Chem. 93, 17-29 (1991).

4. G. Liu and J. Heo, "Generation of white light from oxyfluoride nano-glass doped with $\mathrm{Ho}^{3+}, \mathrm{Tm}^{3+}$ and $\mathrm{Yb}^{3+}$," Mater.
Lett. 61, 3751-3754 (2007).

5. C. Zhu, Y. Yang, X. Liang, S. Yuan, and G. Chen, "Rare earth ions doped full-color luminescence glasses for white LED," J. Lumin. 126, 707-710 (2007).

6. B. Blasse and B. C. Grabmaier, Luminescent Materials (Springer-Verlag, New York, USA, 1994).

7. G. K. DasMohapatra, "A spectroscopic study of cerium in lithium-alumino-borate glass," Mater. Lett. 35, 120-125 (1998).

8. A. Kurita, T. Kushida, T. Izumitani, and M. Matsukawa, "Room-temperature persistent spectral hole burning in $\mathrm{Sm}^{2+}$ -doped fluoride glasses," Opt. Lett. 19, 314-316 (1994).

9. M. B. Volf, Chemical Approach to Glass (Elsevier, Amsterdam, Netherlands, 1984).

10. R. Reisfeld, H. Minti, A. Patra, D. Ganguli, and M. Gaft, "Spectroscopic properties of cerium in glasses and their comparison with crystals," Spectrochim. Acta A 54, 21432150 (1998).

11. J. S. Stroud, "Photoionization of $\mathrm{Ce}^{3+}$ in glass," J. Chem. Phys. 35, 844-850 (1961).

12. J. A. Duffy and Ingram, "An interpretation of glass chemistry in terms of the optical basicity concept," J. Non-Cryst. Solids 21, 373-410 (1976).

13. H. J. Kim and S. C. Choi, "Effect of $\mathrm{Sb}_{2} \mathrm{O}_{3}$ and raw materials on the crystallisation of silver containing glasses," Phys. Chem. Glasses 41, 55-58 (2000).

14. G. Chen, S. Baccaro, M. Nik1, A. Cecilia, Y. Y. Du, and E. Mihokova, "The red-shift of ultraviolet spectra and the relation to optical basicity of Ce-doped alkali rare-earth phosphate glasses," J. Am. Ceram. Soc. 87, 1378-1380 (2004)

15. S. H. M. Poort, J. W. h. van Krevel, R. Stomphorst, A. P. Vink, and G. Blasse, "Luminescence of $\mathrm{Eu}^{2+}$ in host lattices with three alkaline earth ions in a row," J. Solid State Chem. 122, 432-435 (1996).

16. R. Reisfeld, "Spectra and energy transfer of rare-earths in inorganic glasses," Structure \& Bonding 13, 53-98 (1973). 